\title{
Influence of Porosity on Performance of Freeze-granulated $\mathrm{Fe}_{2} \mathrm{O}_{3} / \mathrm{Al}_{2} \mathrm{O}_{3}$ Oxygen Carriers Used for Chemical Looping Combustion
}

\author{
Yi Zhang ${ }^{1}$, Aurora M. Rubel ${ }^{1}$, Sameh Mehrez ${ }^{1}$, James K. Neathery ${ }^{1} \&$ Kunlei Liu ${ }^{1}$ \\ ${ }^{1}$ Center for Applied Energy Research, University of Kentucky, Lexington, USA \\ Correspondence: Kunlei Liu, Center for Applied Energy Research, University of Kentucky, 2540 Research Park \\ Drive, Lexington, KY 40511-8410, USA. Tel: 1-859-257-0267. E-mail: kunlei.liu@uky.edu
}

Received: December 16, 2011 Accepted: December 31, 2011 Online Published: May 29, 2012

doi:10.5539/eer.v2n1p217 URL: http://dx.doi.org/10.5539/eer.v2n1p217

\begin{abstract}
Chemical looping combustion (CLC) is a promising solution for the next coal-fired power generation technology with inherent $\mathrm{CO}_{2}$ separation capability. One of the critical aspects for the development of the CLC process is to develop suitable oxygen carrier (OC) particles to transfer oxygen to the fuel in the absence of air. Relevant studies have focused on active material screening, thermodynamic analysis and operational tests. This investigation was conducted on the microstructural property of OCs, to be specific, the particle porosity effect on the performance of iron-based OCs. $\mathrm{Fe}_{2} \mathrm{O}_{3}$, supported on $\mathrm{Al}_{2} \mathrm{O}_{3}$ was used as the oxygen carrier. The effect of water content of the spray slurry used to produce the $\mathrm{OC}$ was varied to determine the influence of OC porosity on reactivity, oxygen transfer capacity and mechanical durability. A preliminary test was done to establish the minimum and maximum water percentage needed to make slurry. A process that included freeze granulation (FG), freeze drying, and calcination was used to prepare four samples of iron oxide/alumina with various water-to-solid phase ratios. A scanning electron microscope (SEM) was used to characterize the porosity of FG $\mathrm{Fe}_{2} \mathrm{O}_{3} / \mathrm{Al}_{2} \mathrm{O}_{3}$ particles. A direct relationship was observed. A Shimpo FGE-10X force gauge was used to measure the crushing strength of selected samples. A thermogravimetric analyzer (TGA) coupled with a mass spectrometer (MS) was used to study the change in reaction rates through multiple reduction-oxidation cycles of the samples. Crystallinity of the OCs in reduced and oxidized forms were confirmed by XRD analysis.
\end{abstract}

Keywords: chemical looping combustion (CLC), oxygen carrier, porosity

\section{Introduction}

Chemical looping combustion (CLC) is a promising solution being investigated as one of next generation clean coal technologies for greenhouse gas emission control (Anon, 2004; Brandvoll \& Bolland, 2004; Hossain \& de Lasa, 2008; Ishida \& Jin, 1997). CLC's potential is two-fold in that it can provide a high-purity, sequestration-ready stream of $\mathrm{CO}_{2}$ and theoretically provide a substantial improvement in thermal conversion efficiency for fossil-fuel utilization with $\mathrm{CO}_{2}$ capture. CLC uses a solid oxygen carrier (OC), usually a metal oxide to transfer the oxygen from the air (Air Reactor) to the fuel in a reducing reactor (Fuel Reactor) without the direct contact between the fuel and air. The oxygen-depleted OC is recycled by using steam or flue gas in the loop-seal to the Air Reactor where the carrier is oxidized to its original state. In CLC, air does not directly meet the fuel, and so the product stream from the Fuel Reactor is not diluted with the nitrogen in air resulting in a nearly pure $\mathrm{CO}_{2}$ stream after the condensation of $\mathrm{H}_{2} \mathrm{O}$. This high concentration $\mathrm{CO}_{2}$ stream is ready for subsequent sequestration without any additional purification (Freund, 1998).

One of the key tasks for CLC technology development is the development of a suitable oxygen carrier (OC) which transfers oxygen to the fuel from the air reactor to fuel reactor. OCs are different from catalysts since they are involved in fuel oxidation reactionswhich result in its reduction and then needs to be re-oxidized in another reactor. The ideal OC should possess properties such as high reactivity with respect to fuel oxidation and air regeneration for higher overall plan productivity, high oxygen transfer capacity per kilogram mass to minimize the size of reactors, high resistance to particle collision and attrition for longer OC utilization life, low material cost for lower cost of produced energy and low agglomeration tendency. In order to improve performance of OCs, lots of effort has been spent on screening various active materials, including Ni (Hoteit, Chandel, \& Delebarre, 2009; Shen, Wu, Gao, \& Xiao, 2010; Svoboda, Siewiorek, Baxter, Rogut, \& Puncochar, 2007; Wolf, Anheden, \& Yan, 2005), Fe (Cormos, 2010; He, Wang, \& Dai, 2007; Kierzkowska et al., 2010; Kim, Lee, Fan, \& 
Park, 2009; A. Rubel, Zhang, Liu, \& Neathery, 2011; A. M. Rubel, Zhang, Neathery, \& Liu, 2011; Sun et al., 2010; Svoboda, Slowinski, Rogut, \& Baxter, 2007; Yang, Cai, \& Li, 2008), Cu (Adanez et al., 2006; Liu, Simonyi, Sanders, Siriwardane, \& Veser, 2007), Co (De los Rios, Gutierrez, Martinez, \& Ortiz, 2005; Svoboda, Siewiorek, Baxter, Rogut, \& Pohorely, 2008) based metal oxides, and mixtures of these (He et al., 2007; Readman, Olafsen, Larring, \& Blom, 2005). Some studies have been reported adding support materials such as alumina (Adanez et al., 2006; He et al., 2007), zirconia (Scheffe et al., 2011), titania (De los Rios, Gutierrez, Martinez, \& Ortiz, 2005) and silica (Park, Zhang, Hu, \& McFarland, 2010). The purpose of using support is to provide high surface area for loading the active materials. Red-Ox reactions involved in the oxygen transfer process include the solid phase reactions where oxygen diffusion in bulk materials is the rate limiting step and can be several orders of magnitude lower compared to gas phase reactions. Therefore dispersing and providing larger gas-solid contact area to both external and internal surfaces of the OC particles are critical for achieving high reactivity and capacity. On the other hand, increasing porosity is often accompanied by deterioration in mechanical strength and attrition resistance. From the literature, OCs with various porous microstructures have been developed and characterized. Still it is difficult to correlate OCs' performance to porosity due to the variations in the active materials, metal oxide loading, OC preparation method, selection of supports and testing environment among the reports. In this study, the effort was made to prepare and compare a series of OCs with same active material and support, metal oxide loading, and preparation procedure. The porosity of particles was the only variable and adjusted carefully in freeze granulation process. The produced OCs were investigated and compared in gas fuel combustion tests to show the effect of porosity of the OCs on their performance.

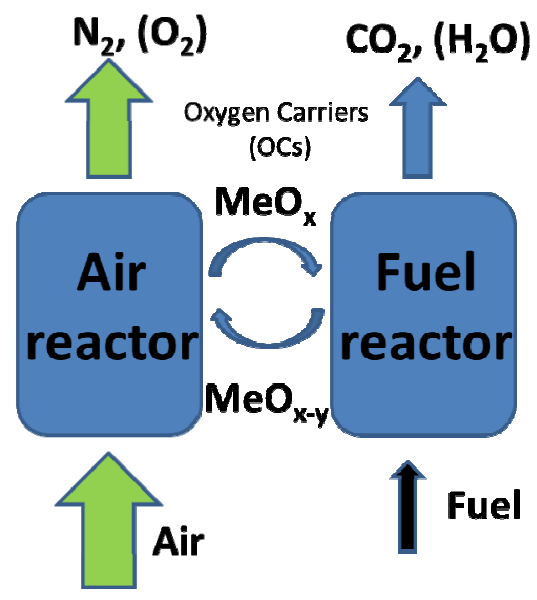

Figure 1. An illustration of chemical looping combustion concept

Freeze granulation has been used to prepare high quality organic/inorganic, metal and ceramic powders. It offers several advantages including uniform porosity and homogeneous composition across particles, adjustable density and size. Mild process condition minimizes oxidation of non-oxides and metals and other influences on the raw materials. Freeze granulation with sequential freeze drying is a technique used to produce nano and micron meter scale granules with homogeneous composition and microstructure. The process is based on instant freezing of sprayed slurry droplets and subsequent freeze drying. The slurry is a powder suspension with pre-determined composition. The granule density is controlled by adjusting solid content in the slurry. The particle size is adjusted through the process parameters in the spraying step such as slurry-to-air flow ratio, slurry viscosity, additives and air pressure. For metal and ceramic materials after proper sintering treatment the mechanical strength of the particles can be improved further if desired.

In this work, the porosity of freeze-granulated OC particles was adjusted through tuning the liquid content in the spray slurry. A series of samples were prepared and tested under identical conditions to isolate porosity influence on the performance of OCs. 


\section{Experimental}

\subsection{Materials}

Commercially available metal oxide powders, $\mathrm{Fe}_{2} \mathrm{O}_{3}$ and $\mathrm{Al}_{2} \mathrm{O}_{3}$ were purchased from Sigma-Aldrich and used as received to prepare oxygen carriers by freeze granulation. Polyvinyl alcohol (Sigma-Aldrich, M.W. 67,000) was used as the binder to adjust the viscosity of slurries used for freeze granulation and to help form spherical particles. DISPEX A40 (V) (Ciba, Switzerland) was used as a dispersant in the slurries. Deionized water (18 $\mathrm{m} \Omega$ ) was used in all the preparations. Ultra high purity gases including $\mathrm{Ar}, \mathrm{CO}, \mathrm{O}_{2}, \mathrm{H}_{2}$ and $\mathrm{CO}_{2}$ were used to blend simulated syngas for gaseous fuel combustion tests.

\subsection{Freeze Granulation}

A slurry was prepared by ball milling a mixture of solids, additives (dispersant and binder) with deionized water. The slurry was pumped via a peristaltic pump to the spray nozzle of the freeze granulator. Pressurized air was also sent to the spray nozzle to combine with the slurry creating a uniform spray mist which was sent into a magnetically stirred container of liquid $\mathrm{N}_{2}$. The spray was regulated by the air pressure and the feed pumping rate of the slurry. This resulted in the production of frozen spherical particles. The size of the spheres (OCs) was adjusted by changing the air pressure, the feed rate, and the composition of the slurry. The metal oxide to alumina loadings used to produce freeze granulated (FG) OCs were 50:50 of wt $/ \mathrm{wt} \%$ for all the samples. The porosity of produced OC particles was adjusted by changing the water content in the spray slurries. With more water inside, after removing the ice by freeze drying, more void volume was left. The water weight percentage based on slurry weight was adjusted to $30 \%, 50 \%, 60 \%$ and $80 \%$. Freeze granulation conditions, pump speed and air pressure, were optimized to maximize the particle yield in the size range desired. The slurries were prepared by ball milling for at least $24 \mathrm{hr}$. Air pressure was adjusted in the range of $40 \sim 60 \mathrm{kPa}$. The slurry flow rate was $23.4 \sim 40 \mathrm{ml} / \mathrm{min}$. FG particles were kept in the frozen state until freeze dried. After freeze drying, the FG OCs were calcined at $1400{ }^{\circ} \mathrm{C}$ for 6 hours to achieve high durability. Samples sieved to $48 \times 150$ mesh particle size samples were tested for extent and rate of oxidation/reduction, Red-Ox recycle capability, and agglomeration resistance by thermal analysis-mass spectrometry (TG-MS).

\subsection{Mechanical Strength}

To test the crushing strength, a custom made test stage was used mounted to a force gauge (Shimpo FGE-10X) with accuracy of $0.01 \mathrm{~N}$ and a movable pin positioned vertically against the force probe of the gauge. The pin was able to be slowly screwed down to crush a particle placed on the flat surface of the force probe. The peak force right before the breakage of the particle (the maximum strength) was recorded as the crushing strength, with units in $\mathrm{N}$. At least 10 readings were collected to get an average crushing strength for each type OC.

\subsection{BET Surface Area}

BET surface area, total pore volume and average pore size of the samples were measured with a Micromeritics TriStar surface analyzer. Samples were first degased at $160{ }^{\circ} \mathrm{C}$ overnight in a Micromeritics VacProp 061. The samples were kept in 0.2 mbar vacuum with $\mathrm{N}_{2}$ protection. After degasing the samples were tested with $\mathrm{N}_{2}$ adsorption at $77 \mathrm{~K}$. Adsorption isotherm curves were analyzed by software.

\subsection{Thermogravimetric Analysis Coupled with Mass Spectrometry}

The TG-MS was a Netzsch STA 449 F3 Jupiter equipped with a water vapor furnace and coupled to an Aeolos QMS403 (Figure 2). It is capable of temperature to $1200{ }^{\circ} \mathrm{C}$ under both steam and dry gases. The MS measured the gases leaving the TG to determine the gas constituents in the evolved stream. Conditions for testing were reducing gases of $10 \% \mathrm{H}_{2}, 15 \% \mathrm{CO}, 20 \% \mathrm{CO}_{2}$ with and without steam and a balance of Ar; oxidizing gases of $20 \% \mathrm{O}_{2}$ in a balance of $\mathrm{Ar}$; and a reaction temperature of $950{ }^{\circ} \mathrm{C}$. Oxidations/reductions were carried out to near completion and at least 3-5 Red-Ox cycles were done per OC. Gas flow rates and switching was controlled by a set of mass flow controllers operated by Lab View software on a dedicated computer. Times for oxidation/reduction and flows were programmed as needed and the entire operation was run 24/7 without intervention. 


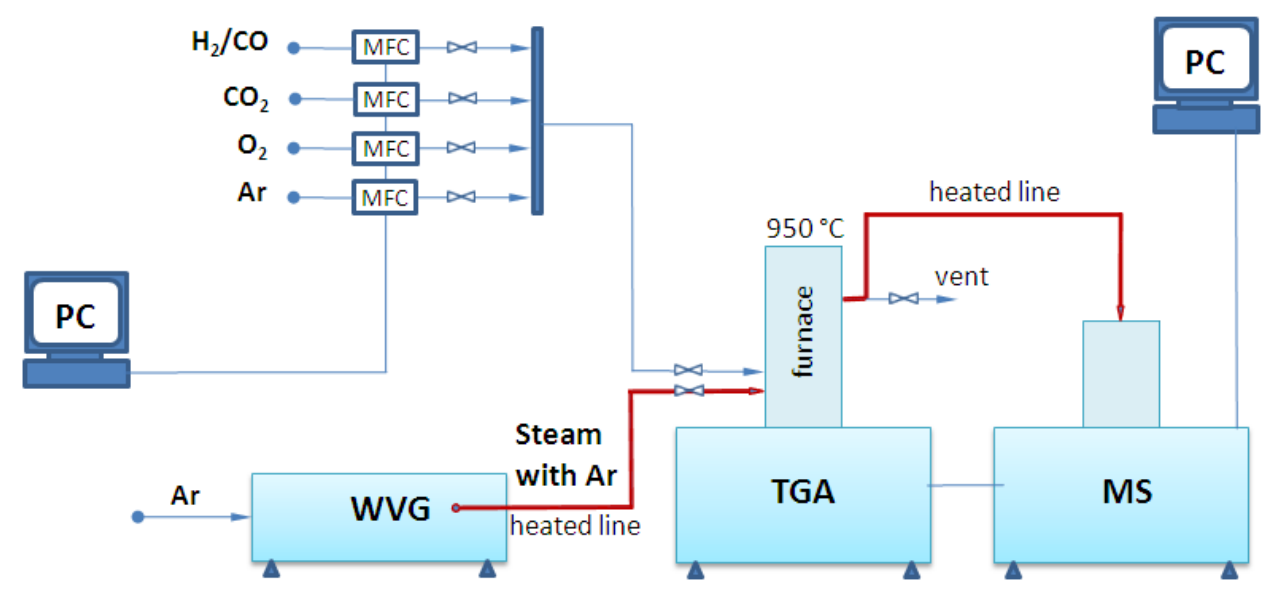

Figure 2. Schematic diagram of the thermogravimetric analyzer-mass spectrometer (TG-MS) system coupled to a water vapor generator (WVG)

\subsection{Microscopic Imaging}

SEM/EDX spectra imaging was performed with a HITACHI S-4800 scanning electron microscopy. The OC particles were immobilized on the sample stage with conducting double sided carbon tapes. To avoid sample charging in imaging due to their nature of low electrical conductivity, 5\% LIQUION solution (Ion Power, Inc.) was used to glue the particles on the aluminum stage to improve electrical contact. Before testing, the samples were coated with a thin layer of carbon in a thermal evaporator to further reduce the charging effect. The accelerating voltage used for all the tests was $15 \mathrm{kV}$.

\section{Results and Discussion}

We have successfully prepared various OCs from iron-, nickel- and copper-based materials through freeze granulation. For each material, optimized active material loadings on alumina support have been explored. We found that for chemical looping combustion of solid fuels, iron-based OCs were the best candidate overall due to its high mechanical strength, moderate reactivity, oxygen carrying capacity, high resistance to water vapor in terms of performance deterioration, cost, and availability. An advantage of freeze granulation is the ability to easily tune the porosity of the resulting particles by simply altering the water content in the slurry. The free volume in the OC particles is directly proportional to the amount of water removed during the freeze drying process. It is important to know the influence of particle porosity for further optimization of the oxygen carrier performance. In this part of the work, four samples were prepared with $50 \% \mathrm{wt} \mathrm{Fe}_{2} \mathrm{O}_{3}$ loading in alumina by free granulation. In slurry preparation, the water-to-solid ratio was varied from $30 \%, 50 \%, 60 \%$ to $80 \%$. The resulting OC samples were examined with crushing test, density test, SEM and TG-MS.

For freeze granulation to work well, the solid loading in the slurry must be below an upper limit. In another word, water content for preparing the slurry has a low limit at which the slurry still has proper flowability to pass the spray nozzle. Thirty \%wt water content was the low boundary determined experimentally. On the other hand, there is an upper limit for water content as well since too little solid loading results in particles which will not be able to sustain their spherical form after the water is removed. To find this upper boundary, several slurries were prepared with decreasing solid loading, $30 \%, 50 \%, 60 \%$ and $80 \%$.

The SEM images for $30 \%, 50 \%$ and $80 \%$ samples can be found in Figure 3. All the samples exhibited porous microstructure with interpenetrated void channels, which is crucial to providing sufficient gas-solid contact surface to achieve faster and more complete Red-Ox reactions. The OC samples prepared from slurries with $30 \%$, $50 \%$ and $60 \%$ were found to be able to sustain a spherical form after water and organic additives were removed by freeze drying and calcination. However, the $80 \%$ sample showed a significant difference from the other samples and no spherical or individual particles in 100-300 micron range were found, though it had much higher porosity compared to other samples. 

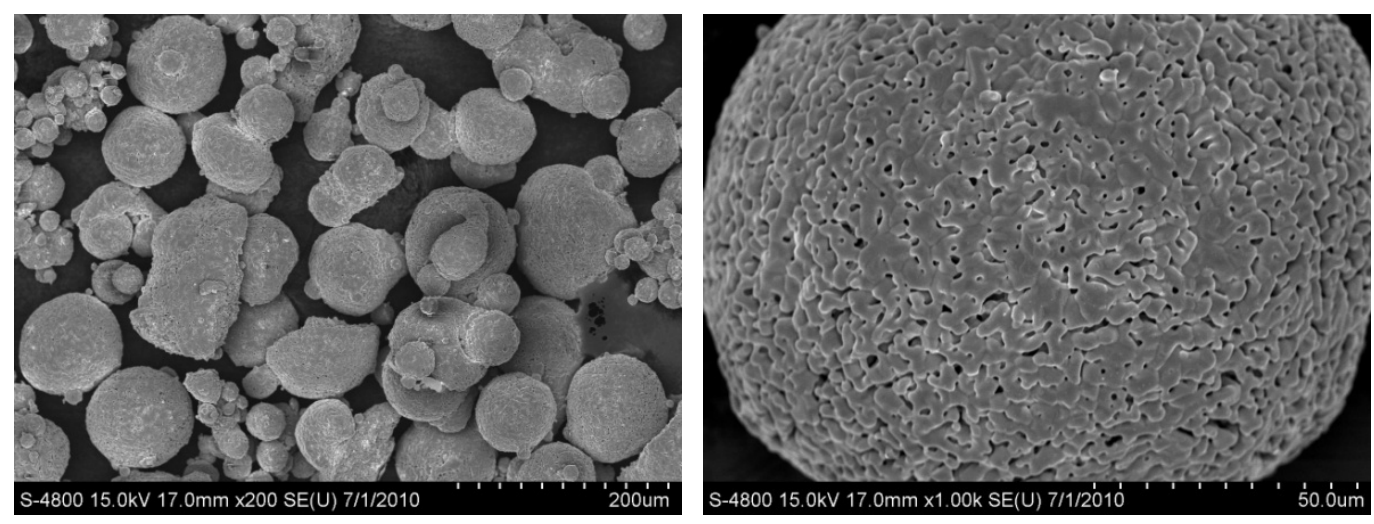

OC sample from slurry with $\mathbf{3 0} \%$ water inspected at two magnifications
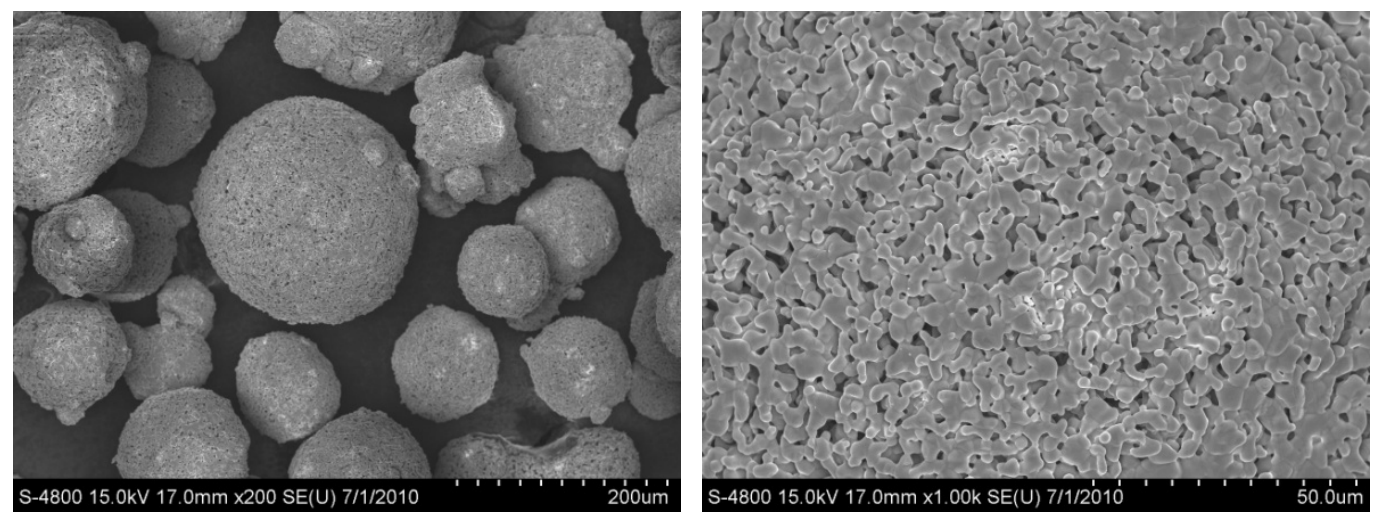

OC sample from slurry with $\mathbf{5 0 \%}$ water inspected at two magnifications
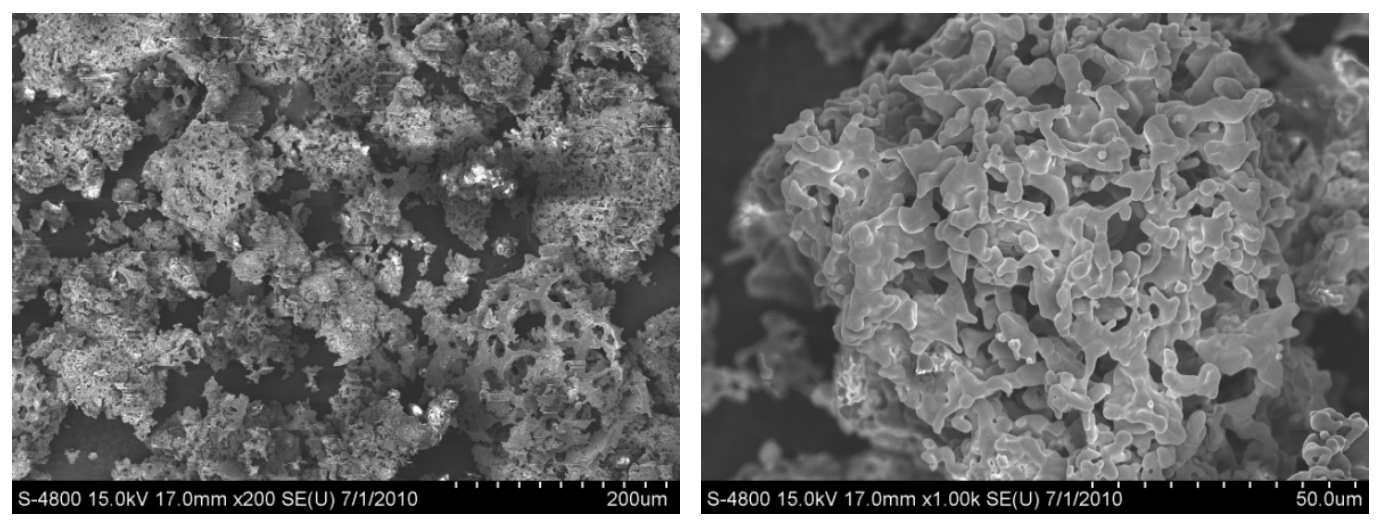

OC sample from slurry with $\mathbf{8 0} \%$ water inspected at two magnifications

Figure 3. SEM images of freeze-granulated 50\% iron-based OCs with increasing water content in starting slurries. The scale bars can be found in the lower right of the images

The packing density was first measured for the four samples followed by the crushing strength test which was carried out following the procedure stated in a reference (Leion et al., 2009). Briefly, a single particle was crushed using the force gauge. For each OC sample, at least 10 particles were crushed and the average crushing force was reported as the sample crushing strength along with its standard deviation. The results were summarized in Figure 4. The density was significantly reduced as the porosity of the particles increased. 


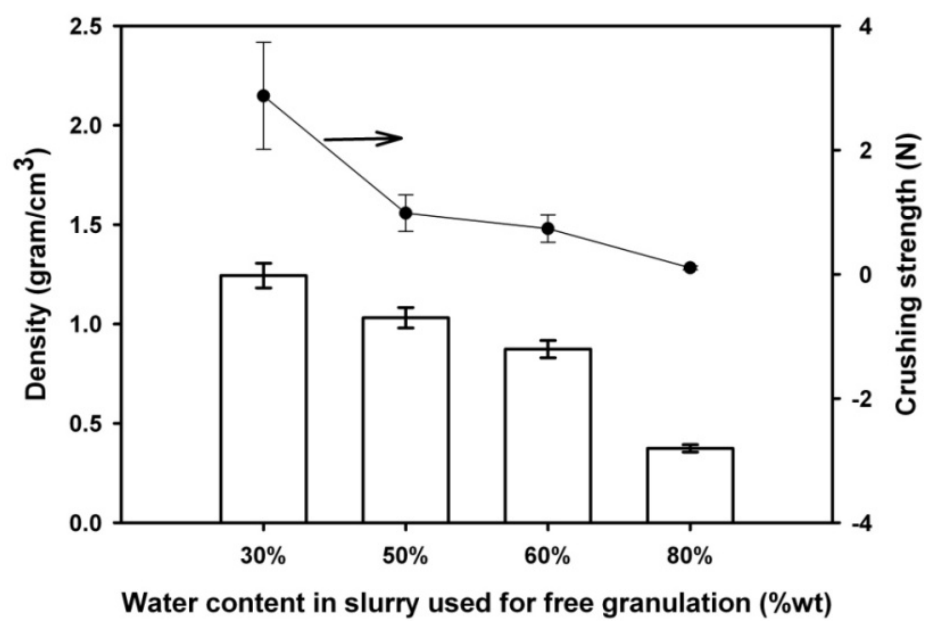

Figure 4. Particle density and crushing strength of the OC samples prepared from slurries with varying water content

The packing density presented a clear inverse correlation with increased slurry water content. This was consistent with the assumption that for the freeze granulation process the more water in the frozen particles removed during freeze drying, the more void volume was left inside the particles and the higher the porosity. This result indicated that adjusting the water content of the slurry was an effective and easy way to fine tune the OC particle porosity. BET surface area measurements on the samples also show that the surface areas of the four samples range from 0.25 to $0.45 \mathrm{~cm}^{3} /$ gram as in Table 1. Surprisingly the BET surface area of the $80 \%$ sample was not significantly higher than the $60 \%$ sample. BET method characterizes mesopores and nanopores with good accuracy. However, the pores inside OCs in our study were larger submicron pores, as observed in the SEM images.

Table 1. Microstructure analysis: BET surface area, total pore volume and average pore size

\begin{tabular}{|c|c|c|c|}
\hline & $\begin{array}{l}\text { BET surface area } \\
\left(\mathrm{cm}^{2} / \mathrm{g}\right)\end{array}$ & $\begin{array}{l}\text { Total pore volume } \\
\qquad\left(\mathrm{cm}^{3} / \mathrm{g}\right)\end{array}$ & $\begin{array}{c}\text { Average pore size } \\
\text { (nm) }\end{array}$ \\
\hline FG-30 & 0.2529 & 0.000802 & 6.3428 \\
\hline FG-50 & 0.4336 & 0.001445 & 6.6648 \\
\hline FG-60 & 0.3479 & 0.001280 & 6.6583 \\
\hline FG-80 & 0.3247 & 0.001017 & 5.8425 \\
\hline
\end{tabular}

The crushing strength indicated a declining trend as well with increasing slurry water content. Considering the microstructure inside the particles, more free volume suggests less interconnections and joints in the solid phase, and therefore, less mechanical strength. Since the mechanical strength is a crucial factor in choosing an OCs for fluidized bed operations, strong particles are desirable. Based on the results less porous OCs had higher mechanical strength. However, there is always a concern that less porous surface reduces the accessible reactive area, and therefore, reduces reactivity and capacity of the materials. In order to provide information for making a decision regarding the tradeoff between these two factors, the samples were examined by TG-MS.

The four samples were evaluated by TG-MS by standard procedures. Briefly, a known amount of OC sample was loaded on a crucible in the TG oven. The weight change of the OC loadings was monitored during alternating Red-Ox gases to simulate the processes in the air and fuel reactors. In the reduction cycles, the gas contained $10 \% \mathrm{H}_{2}, 15 \% \mathrm{CO}$, and $20 \% \mathrm{CO}_{2}$ with a balance of Ar was purged through the TG oven. In oxidation cycles, $20 \% \mathrm{O}_{2}$ in $\mathrm{Ar}$ was used. In reduction cycles, the OC samples release oxygen atoms from metal oxides and lost weight. In oxidation cycles, the reverse process happened. Enough time was given to allow the Red-Ox reactions to go to near completion. 


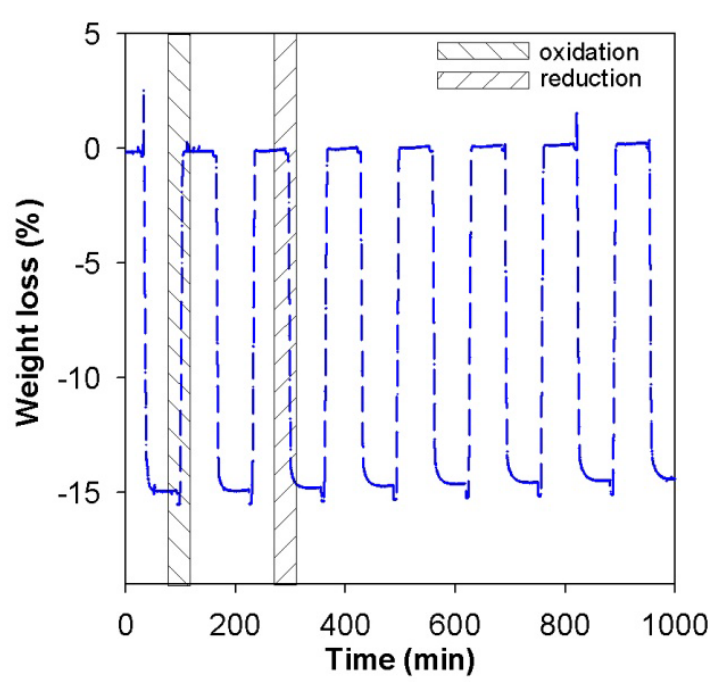

(a) TGA weight change curve from alternating Red-Ox cycles

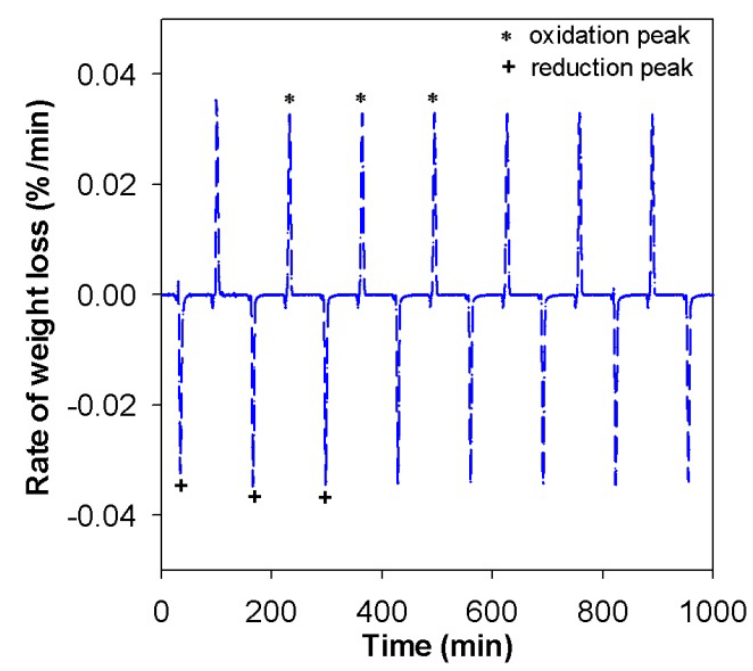

(b) DTA weight change rate curve from the same test

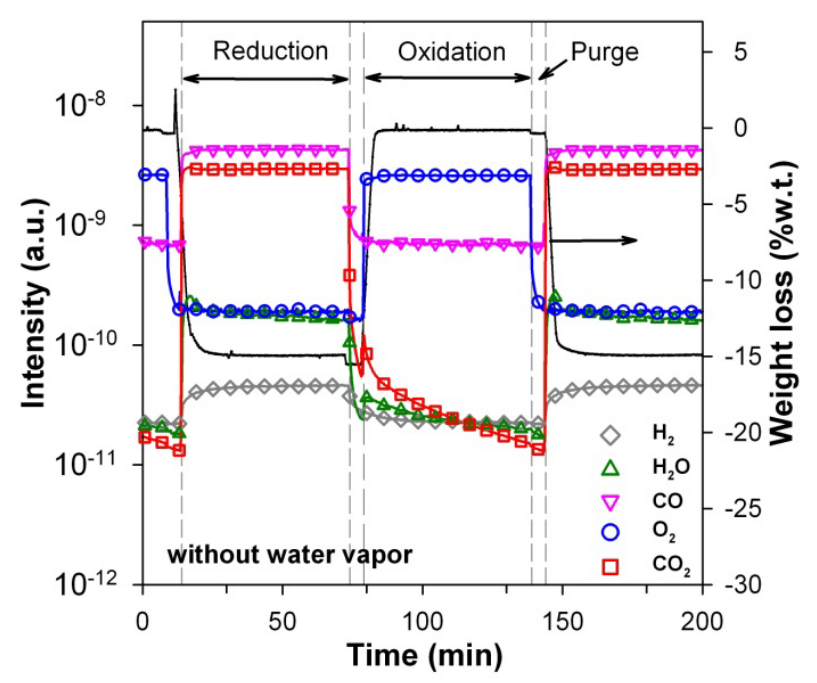

(c) Mass spectrum of the exhaust gas

Figure 5. Oxygen carrier evaluation by TG-MS 
A typical TG-MS test on the freeze-granulated OC is illustrated in Figure 5. The oxygen transfer capacity was derived from the weight change curve. In the reduction cycles, or gas fuel combustion step, the OC was reduced to its less oxidized form by $\mathrm{CO}$ and $\mathrm{H}_{2}$ in the simulated syngas and the lost weight loss is due to released oxygen. After a 5-minutepurge with Ar, the reduced $\mathrm{OC}$ was exposed to oxygen to re-oxidize the metal oxide to its higher oxidation state. The weight difference in the cycles was a direct measurement of released $\mathrm{O}$ from the OC particles, as shown in Figure 5(a). The reactivity of the OCs weas characterized by the rate of the weight change obtained from the derivative of weight change curve with respect to time, as shown in Figure 5(b).

The exhaust gas composition was monitored as Red-Ox reactions progressed by the mass spectrometer in Figure 5(c). $\mathrm{H}_{2}, \mathrm{CO}, \mathrm{CO}_{2}$ and $\mathrm{H}_{2} \mathrm{O}$ were detected in the reduction cycle, while $\mathrm{O}_{2}, \mathrm{CO}, \mathrm{CO}_{2}$ and $\mathrm{H}_{2} \mathrm{O}$ were observed in the oxidation cycle. In the syngas combustion, $\mathrm{CO}$ and $\mathrm{H}_{2}$ reduced iron oxide of the $\mathrm{OC}$ particles and produced $\mathrm{CO}_{2}$ and $\mathrm{H}_{2} \mathrm{O}$. In re-oxidation of OC particles, $\mathrm{O}_{2}$ was consumed for both iron oxidation and deposited carbon burn-off. A small amount of $\mathrm{CO}_{2}$ was observed in the early stage of the cycle. Between cycles, $\mathrm{O}_{2}$ and $\mathrm{H}_{2}$ concentration were closely monitored in the purge steps to avoid explosion.

Weight loss curves of four samples with various porosities were plotted in Figure 6 for oxygen transfer capacity comparison. All the curves show reductions took longer than oxidation for iron oxide. The reductions were all completed in less than 10 minutes. The weight changes of the four samples were close to $3.5 \%$ based on fully oxidized OCs. After correcting the percentage to pure iron oxide base, the weight changes were about 7 9\%. The theoretic weight loss from $\mathrm{Fe}_{2} \mathrm{O}_{3}$ to $\mathrm{Fe}_{3} \mathrm{O}_{4}$ transition is $3.34 \%, 10.02 \%$ to $\mathrm{FeO}$ and $30.06 \%$ to Fe. The TGA revealed that the $\mathrm{OC}$ samples were reduced to mixtures of $\mathrm{Fe}_{3} \mathrm{O}_{4}$ and $\mathrm{FeO}$. The results suggested that the porosity range of the samples is suitable for OCs being used in the fluidized bed fuel reactor (FBR). Residence time of OC particles in FBR has been suggested to be less than 30 minutes.

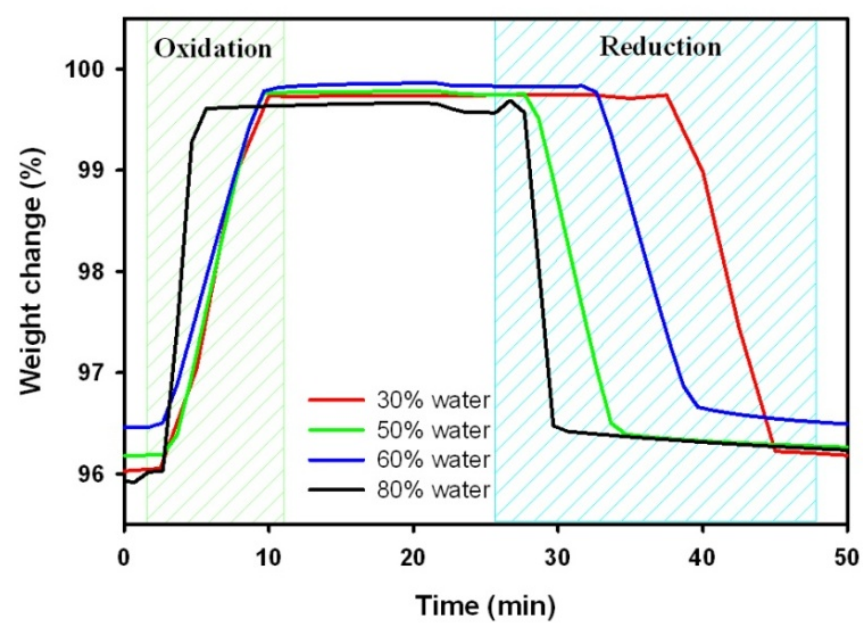

Figure 6. Weight changes of the $\mathrm{OC}$ samples in alternating Red-Ox cycles. In the reduction cycles, simulated gas containing $10 \% \mathrm{H}_{2}, 15 \% \mathrm{CO}, 20 \% \mathrm{CO}_{2}$ with balance Ar was purging through the TG oven. In oxidation cycles, $20 \% \mathrm{O}_{2}$ in $\mathrm{Ar}$ was used

Crystallinity of reduced and re-oxidized FG OCs were examined by XRD. The result showed that $\mathrm{FeAl}_{2} \mathrm{O}_{4}$ was the major phase of the reduced FG OC particles as in Table 2, which can be considered stoichiometrically as the combination of equal parts of $\mathrm{FeO}$ with $\mathrm{Al}_{2} \mathrm{O}_{3}$. The high experimental temperature of $950{ }^{\circ} \mathrm{C}$ was close to the sintering temperature resulting in the formation of a more stable phase, $\mathrm{FeAl}_{2} \mathrm{O}_{4}$. TGA results agreed with XRD crystal analysis, but also suggested that $\mathrm{Fe}_{2} \mathrm{O}_{3}$ was only partially reduced because the weight loss of $7 \sim 8 \%$ was less than the theoretical loss of $10.02 \%$ for fully conversion to $\mathrm{FeO}$. XRD results from the re-oxidized OCs showed primarily $\mathrm{FeAlO}_{3}$, which is combination of equal amounts of $\mathrm{Fe}_{2} \mathrm{O}_{3}$ with $\mathrm{Al}_{2} \mathrm{O}_{3}$. Again the material formed a more thermodynamically favored single crystal phase at high temperature. 
Table 2. XRD analysis of the reduced and oxidized FG

\begin{tabular}{lcc}
\hline & Re-Oxidized & Reduced \\
\hline FG FeO (50\% water) & $\mathrm{FeAlO}_{3}$ & $\mathrm{FeAl}_{2} \mathrm{O}_{4}$ \\
& $\left(\mathrm{Fe}_{2} \mathrm{O}_{3}: \mathrm{Al}_{2} \mathrm{O}_{3}=1: 1\right)$ & $\left(\mathrm{FeO}: \mathrm{Al}_{2} \mathrm{O}_{3}=1: 1\right)$ \\
\hline
\end{tabular}

The reactivity of the samples was compared by differential thermal analysis (DTA) curves in Figure 7. The results clearly showed that the $80 \%$ samplewith the highest porosity had the fastest weight change rate in both reduction (peak at $0.6 \% / \mathrm{min}$ ) and oxidation (peak at $0.65 \% / \mathrm{min}$ ). However, the other three samples showed much smaller difference in rates. Their reduction rates varied in the range of $0.41-0.50 \% / \mathrm{min}$ and oxidation rate from $0.42-0.51 \% / \mathrm{min}$ which were about $30 \%$ lower compared to the $80 \%$ sample.

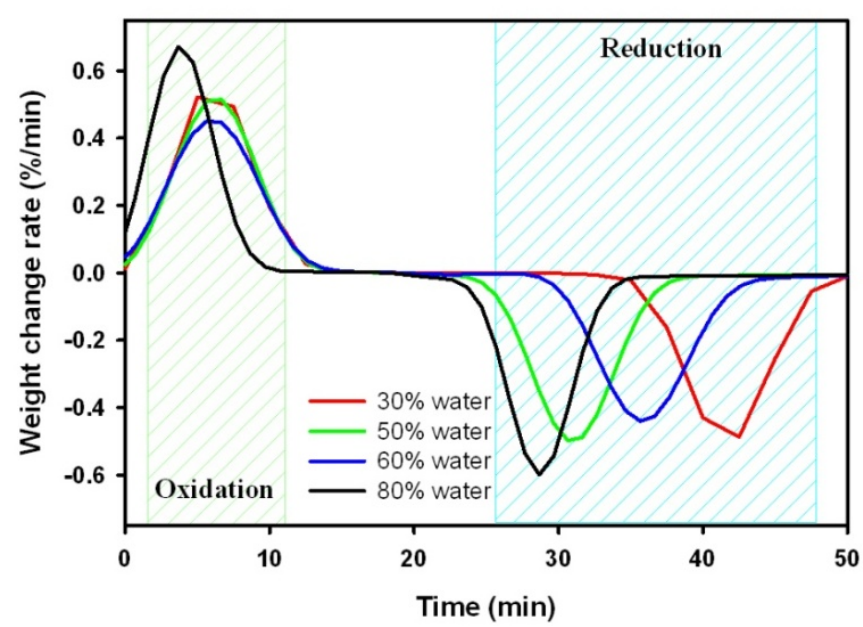

Figure 7. Derivatives of weight changes of the OC samples in alternating Red-Ox cycles

Although the $80 \%$ sample had the best reactivity, the low mechanical strength prevents it from being a suitable candidate for fluidized bed operations. Furthermore, all the OC samples were able to complete reduction and oxidation reactions in less than 10 minutes, which is similar to reported values obtained from pilot scale CLC units.

An ideal oxygen carrier should possess a collection of properties to enable use in extreme conditions such as high combustion temperature, high speed and frequent particle conveying between two fluidized bed reactors and other system parts such as cyclones, pipes and corners. It must also have high reactivity for thermo or electrical productivity and high oxygen transfer capacity for smaller reactor size. Choosing an oxygen carrier requires balancing these aspects and sometimes trade-offs are necessary. In this study the results show that by changing the slurry conditions for freeze granulation, the porosity of the produced particles can be adjusted in a wide range. The number of submicron pores was significantly increased as evidenced in SEM images and apparent density measurements. The BET results show that nanopores and mesopores sizes, and total pore volume of the four samples were very close. This explains why the samples all had relatively low BET surface area values. In high temperature combustion processes where the operation temperature is close to material sintering temperature, nanopores and mesopores are not sustainable. It is also unnecessary since different from catalysis processes, the Red-Ox reactions involved in chemical looping combustion take place mainly in the bulk phase of the solids instead of on the catalyst's surface in order to fully utilize available oxygen and metal atoms. However, certain amount of porosity of particles is critical to achieve high reactivity, in another word, improved rate of reactions. Diffusivity of $\mathrm{O}_{2}$ in air is 10 orders of magnitude higher than that of oxygen ion in metal oxides (Tian et al., 2008). It is important to ensure that OC particles have interconnecting gas channels inside. It has been observed that for low melting point materials as $\mathrm{CuO}$ and $\mathrm{NiO}$ operated above $950{ }^{\circ} \mathrm{C}$, sintering occurred and porosity decreased. This change in microstructure causes significant deterioration in both Red-Ox reactivity and oxygen transfer capacity because of gas channel closure and increased bulk phase diffusion for oxygen ions. In these cases a strong support phase is usually needed to sustain the particle's microstructure. The materials 
common used as supports are $\mathrm{Al}_{2} \mathrm{O}_{3}, \mathrm{SiO}_{2}, \mathrm{ZrO}_{2}$ and $\mathrm{TiO}_{2}$. However, if not well dispersed the active materials still have tendency to coarsen which causes grain size growth, loss of surface area and porosity. From this study it also suggests that without fine tuning nano/meso-scale pores the FG OCs already have reasonable reactivity and capacity. Pores in nano/meso scale are highly likely to be smooth out by sintering under high temperature after just several Red-Ox cycles.

Mechanical strength is another important factor to consider in OC development. OC regeneration usually takes place in a circulating fluidized bed (CFB) where the particle velocity is higher. Particles attrition can be a big issue when CLC technology goes to commercial scale reactors. Mechanical strength of particles is correlated directly to attrition resistance. The tests result showed that the strength of the most porous OC $(80 \%$ water sample) was two orders of magnitude lower than the least porous OC ( $30 \%$ water sample). Considering that the less porous OCs only lost $20 \sim 30 \%$ of its reactivity and the capacity remained similar while gaining orders of magnitude higher mechanical strength, the less porous OCs are favored for the operation. In this study, a water content of $50 \sim 60 \%$ in the spray slurry was considered the optimum range for the synthetic OC freeze granulation.

\section{Conclusions}

The study focused on the effect of porosity on oxygen carrier performance in chemical looping combustion. A series of Fe-based oxygen carriers with different porosity were prepared by simply adjusting the water content of the spray slurry used for freeze granulation. The properties of OCs were measured including apparent density, crushing strength, BET surface area, Red-Ox reactivity, and oxygen transfer capacity.

The results showed that OC particles with higher porosity have $30 \%$ higher reactivity, but 2 orders of magnitude lower mechanical strength. The less porous materials show acceptable reactivity and much better strength and compact volume, which offer potential advantages such as long life time, ease of separation from ash based on density difference, and smaller equipment sizes.

1. Porosity of OC particles can be easily controlled in freeze granulation by adjusting the water content in the spray slurry. This process can be used to adjust the number of submicron or larger pores. However, size and total volume of nanopores and mesopores were not affected by the freeze granulation procedure.

2. Adequate porosity was helpful in improving the reactivity of the solid gas Red-Ox reactions. The most porous OC showed $30 \%$ higher reactivity in both reduction and oxygen reactions than the least porous OC. However, after a certain level, increased porosity does not yield higher Red-Ox reactivity as observed from the samples prepared with $80 \%$ water content. The oxygen transfer capacity was not influenced by the porosity significantly since even for the least porous sample the interpenetrating gas channels are sufficient for delivery of gaseous reactants and diffusion of products inside OC particles.

3. Porosity of the OC particles had an influence on OC's apparent density and mechanical strength. Crushing force from the least porous OC was two orders of magnitude higher than the most porous OC.

4. To determine optimized porosity of the OC produced from freeze granulation, a variety of properties need to be taken account. OCs prepared from slurry with $50 \sim 60 \%$ water content was considered to be the suitable range. The OCs produced had high reactivity, oxygen transfer capacity, and strong mechanical structure needed in CFB and FBR operations.

\section{Acknowledgments}

The authors thank generous funding support for this work from the Carbon Management Research Group, including American Electric Power, Big Rivers Electric Corporation, Duke Energy, East Kentucky Power COOP, EON US, Electric Power Research Institute, and Kentucky Dept. of Energy Development and Independence.

\section{References}

Adanez, J., Gayan, P., Celaya, J., de Diego, L. F., Garcia-Labiano, F., \& Abad, A. (2006). Chemical looping combustion in a $10 \mathrm{~kW}\left(\right.$ th) prototype using a $\mathrm{CuO} / \mathrm{Al}_{2} \mathrm{O}_{3}$ oxygen carrier: Effect of operating conditions on methane combustion. Industrial \& Engineering Chemistry Research, 45(17), 6075-6080. http://dx.doi.org/10.1021/ie0603641

Anonymous. (2004). The promise of chemical looping. Power, 148(6), 10.

Brandvoll, O., \& Bolland, O. (2004). Inherent $\mathrm{CO}_{2}$ capture using chemical looping combustion in a natural gas fired power cycle. Journal of Engineering for Gas Turbines and Power-Transactions of the Asme, 126(2), 316-321. http://dx.doi.org/10.1115/1.1615251 
Cormos, C. C. (2010). Evaluation of iron based chemical looping for hydrogen and electricity co-production by gasification process with carbon capture and storage. International Journal of Hydrogen Energy, 35(6), 2278-2289. http://dx.doi.org/10.1016/j.ijhydene.2010.01.033

De los Rios, T., Gutierrez, D. L., Martinez, V. C., \& Ortiz, A. L. (2005). Redox stabilization effect of $\mathrm{TiO}_{2}$ in $\mathrm{Co}_{3} \mathrm{O}_{4}$ as oxygen carrier for the production of hydrogen through POX and chemical looping processes. International Journal of Chemical Reactor Engineering, 3, A33. http://dx.doi.org/10.2202/1542-6580.1260

Freund, P. (1998). Abatement and Mitigation of Carbon Dioxide Emissions from Power Generation. Powergen 98 Conference, Milan.

He, F., Wang, H., \& Dai, Y. N. (2007). Application of $\mathrm{Fe}_{2} \mathrm{O}_{3} / \mathrm{Al}_{2} \mathrm{O}_{3}$ composite particles as oxygen carrier of chemical looping combustion. Journal of Natural Gas Chemistry, 16(2), 155-161. http://dx.doi.org/10.1016/S1003-9953(07)60041-3

Hossain, M. M., \& de Lasa, H. I. (2008). Chemical-looping combustion (CLC) for inherent $\mathrm{CO}_{2}$ separations-a review. Chemical Engineering Science, 63(18), 4433-4451. http://dx.doi.org/10.1016/j.ces.2008.05.028

Hoteit, A., Chandel, M. K., \& Delebarre, A. (2009). Nickel- and Copper-Based Oxygen Carriers for Chemical Looping Combustion. Chemical Engineering \& Technology, 32(3), 443-449. http://dx.doi.org/10.1002/ceat.200800322

Ishida, M., \& Jin, H. (1997). $\mathrm{CO}_{2}$ recovery in a power plant with chemical looping combustion. Energy Conversion and Management, 38, S187-S192. http://dx.doi.org/10.1016/S0196-8904(96)00267-1

Kierzkowska, A. M., Bohn, C. D., Scott, S. A., Cleeton, J. P., Dennis, J. S., \& Muller, C. R. (2010). Development of Iron Oxide Carriers for Chemical Looping Combustion Using Sol-Gel. Industrial \& Engineering Chemistry Research, 49(11), 5383-5391. http://dx.doi.org/10.1021/ie100046f

Kim, H. R., Lee, D. H., Fan, L. S., \& Park, A. H. A. (2009). Synthesis of Iron-Based Chemical Looping Sorbents Integrated with $\mathrm{pH}$ Swing Carbon Mineral Sequestration. Journal of Nanoscience and Nanotechnology, 9(12), 7422-7427. http://dx.doi.org/10.1166/jnn.2009.1754

Leion, H., Larring, Y., Bakken, E., Bredesen, R., Mattisson, T., \& Lyngfelt, A. (2009). Use of $\mathrm{CaMn}_{(0.875)} \mathrm{Ti}_{(0.125)} \mathrm{O}_{(3)}$ as Oxygen Carrier in Chemical-Looping with Oxygen Uncoupling. Energy \& Fuels, 23, 5276-5283. http://dx.doi.org/10.1021/ef900444d

Liu, T. F., Simonyi, T., Sanders, T., Siriwardane, R., \& Veser, G. (2007). Comparative evaluation of Ni-, Cu-, and Fe-based oxygen carriers for chemical looping combustion. Abstracts of Papers of the American Chemical Society, 233, 239-239.

Park, J. N., Zhang, P., Hu, Y. S., \& McFarland, E. (2010). Synthesis and characterization of sintering-resistant silica-encapsulated $\mathrm{Fe}_{3} \mathrm{O}_{4}$ magnetic nanoparticles active for oxidation and chemical looping combustion. Nanotechnology, 21(22), 225708. http://dx.doi.org/10.1088/0957-4484/21/22/225708

Readman, J. E., Olafsen, A., Larring, Y., \& Blom, R. (2005). $\mathrm{La}_{0.8} \mathrm{Sr}_{0.2} \mathrm{Co}_{0.2} \mathrm{Fe}_{0.8} \mathrm{O}_{3}$-delta as a potential oxygen carrier in a chemical looping type reactor, an in-situ powder X-ray diffraction study. Journal of Materials Chemistry, 15(19), 1931-1937. http://dx.doi.org/10.1039/b416526h

Rubel, A., Zhang, Y., Liu, K., \& Neathery, J. (2011). Effect of Ash on Oxygen Carriers for the Application of Chemical Looping Combustion to a High Carbon Char. Oil \& Gas Science and Technology-Revue D Ifp Energies Nouvelles, 66(2), 291-300.

Rubel, A. M., Zhang, Y., Neathery, J. K., \& Liu, K. L. (2011). Effect of Water Vapor on the Redox Reactions of Iron-Based Oxygen Carriers for Chemical Looping Combustion. Energy \& Fuels, 25(10), 4271-4279. http://dx.doi.org/10.1021/ef2008198

Scheffe, J. R., Allendorf, M. D., Coker, E. N., Jacobs, B. W., McDaniel, A. H., \& Weimer, A. W. (2011). Hydrogen Production via Chemical Looping Redox Cycles Using Atomic Layer Deposition-Synthesized Iron Oxide and Cobalt Ferrites. Chemistry of Materials, 23(8), 2030-2038. http://dx.doi.org/10.1021/cm103622e

Shen, L. H., Wu, J. H., Gao, Z. P., \& Xiao, J. (2010). Characterization of chemical looping combustion of coal in a $1 \mathrm{~kW}($ th) reactor with a nickel-based oxygen carrier. Combustion and Flame, 157(5), 934-942. http://dx.doi.org/10.1016/j.combustflame.2009.10.009

Sun, X. Y., Xiang, W. G., Wang, S., Tian, W. D., Xu, X., Xu, Y. J., et al. (2010). Investigation of Coal Fueled Chemical Looping Combustion Using $\mathrm{Fe} 3 \mathrm{O} 4$ as Oxygen Carrier: Influence of Variables. Journal of 
Thermal Science, 19(3), 266-275. http://dx.doi.org/10.1007/s11630-010-0266-3

Svoboda, K., Siewiorek, A., Baxter, D., Rogut, J., \& Pohorely, M. (2008). Thermodynamic possibilities and constraints for pure hydrogen production by a nickel and cobalt-based chemical looping process at lower $\begin{array}{lllll}\text { temperatures. Energy Conversion and } & \text { Management, } 21-231 .\end{array}$ http://dx.doi.org/10.1016/j.enconman.2007.06.036

Svoboda, K., Siewiorek, A., Baxter, D., Rogut, J., \& Puncochar, M. (2007). Thermodynamic possibilities and constraints of pure hydrogen production by a chromium, nickel, and manganese-based chemical looping process at lower temperatures. Chemical Papers, 61(2), 110-120. http://dx.doi.org/10.2478/s11696-007-0007-6

Svoboda, K., Slowinski, G., Rogut, J., \& Baxter, D. (2007). Thermodynamic possibilities and constraints for pure hydrogen production by iron based chemical looping process at lower temperatures. Energy Conversion and Management, 48(12), 3063-3073. http://dx.doi.org/10.1016/j.enconman.2007.05.019

Tian, H. J., Chaudhari, K., Simonyi, T., Poston, J., Liu, T. F., Sanders, T., et al. (2008). Chemical-looping Combustion of Coal-derived Synthesis Gas Over Copper Oxide Oxygen Carriers. Energy \& Fuels, 22(6), 3744-3755. http://dx.doi.org/10.1021/ef800438x

Wolf, J., Anheden, M., \& Yan, J. Y. (2005). Comparison of nickel- and iron-based oxygen carriers in chemical looping combustion for $\mathrm{CO} 2$ capture in power generation. Fuel, 84(7-8), 993-1006. http://dx.doi.org/10.1016/j.fuel.2004.12.016

Yang, J. B., Cai, N. S., \& Li, Z. S. (2008). Hydrogen production from the steam-iron process with direct reduction of iron oxide by chemical looping combustion of coal char. Energy \& Fuels, 22(4), 2570-2579. http://dx.doi.org/10.1021/ef800014r 